\title{
MARGENS DA HISTÓRIA E DA FICĈ̃̃: FRAGMENTAÇ̃̃O E IDEOLOGIA EM WALTER BENJAMIN E GUIMARÃES ROSA
}

Gilmário Guerreiro da Costa

\begin{abstract}
RESUMO
Propõe-se neste artigo uma análise das relações entre fragmentação e ideologia nas Teses sobre a filosofia da história, de Walter Benjamin, e no Grande sertão: veredas, de João Guimarães Rosa. Em que pesem as diferenças importantes de foco e estilo entre essas obras, os dois escritores guardam em comum a coerência entre a matéria do seu compromisso crítico e a estruturação fragmentária com a qual teceram cuidadosamente os seus textos. No romance de Rosa, isso se evidencia pela construção do enredo e os aforismos que pontuam momentos diversos da narrativa; nas teses benjaminianas, pela montagem das seções e das frases, infensas a uma harmonia e articulação estreitas que findariam por ocultar as contradições da própria realidade história. Com semelhante procedimento, tais experiências buscam contribuir à crítica da ideologia e ao delineamento de espaços por onde ainda se insinuariam possibilidades utópicas. Não se excluem os aspectos trágicos do exercício, que manifestam a peculiaridade da recepção da cultura clássica nos dois autores.
\end{abstract}

Palavras-chave: Ideologia, fragmentação, tragicidade, Walter Benjamin, Guimarães Rosa.

\section{HISTORY AND FICTION SCOPE: FRAGMENTATION AND IDEOLOGY IN WALTER BENJAMIN AND GUIMARAES ROSA ABSTRACT}

It is proposed in this paper an analysis of the relationship between fragmentation and ideology in the Theses on the philosophy of history, by Walter Benjamin, and the novel Grande sertão: veredas, by João Guimarães Rosa. Notwithstanding the important differences in their focus and style, the two writers have in common the coherence between the matter of their critical engagement and the fragmentary structure with which they wove carefully their texts. In Rosa's novel, such feature manifests in the construction of the plot and the aphorisms present at the different levels of the story; in the Benjamin's theses, by the assembly of sections and phrases resistant to harmony and close articulation which would conceal the historical reality. Such textual experiments may contribute to the critique of ideology and to outline some utopian possibilities. Tragic aspects also are present in these exercises, which manifest the peculiarity of the reception of the Classical culture by the two writers.

Keywords: Ideology, fragmentation, tragic, Walter Benjamin, Guimarães Rosa.

Gilmário Guerreiro da Costa - Pós-doutor pela Cátedra UNESCO Archai, da Universidade de Brasília. Pós doutorando no Centro de Estudos Clássicos e Humanísticos da Universidade de Coimbra. Professor da Universidade Católica de Brasília. Brasileiro, residente em Distrito Federal - Brasília, E-mail: gilmario.filosofia@gmail.com 
1.

A busca por subverter o discurso ideológico como tática de dissimulação política recebeu contribuições variadas ao longo do século XX. Um modo especialmente fecundo de fazê-lo, por sua força política e crítica, divisa-se no enfrentamento e desmontagem dos móveis ideológicos da linguagem mediante a fragmentação da escrita, que se insurge contra os gestos legitimadores de certo modo de contar a história por força de uma narrativa marcada pela continuidade. Os textos Teses sobre a filosofia da história, de Walter Benjamin (redigido em 1940), e o Grande sertão: veredas, de João Guimarães Rosa (publicado em 1956), são férteis em sugestões nesse sentido. No primeiro caso, por revelar o teor ideológico do historicismo, assentado em uma noção de tempo tanto linear, quanto triunfalista, com a qual se tenta justificar o discurso dos vencedores e a inexorabilidade do movimento histórico; no segundo caso, por sustentar uma releitura, por via ficcional, da história brasileira a partir do que há de fraturado e sofrido em seu itinerário.

Os dois escritores guardam em comum, especialmente, a coerência entre a matéria do seu compromisso crítico, e a estruturação fragmentária com a qual teceram cuidadosamente os textos. No romance de Rosa, tal se evidencia pela construção do enredo e os aforismos que pontuam diferentes momentos da narrativa; nas teses benjaminianas, pela montagem das seções e das frases, infensas a uma harmonia e articulação estreitas que findariam por ocultar as contradições da própria realidade histórica. Por meio deste procedimento, estas experiências buscam contribuir à crítica da ideologia e ao delineamento de espaços por onde ainda se insinuariam possibilidades utópicas. Não se excluem os aspectos trágicos do exercício, que manifestam a peculiaridade da recepção da cultura clássica nos dois autores.

\section{2.}

Convém à elaboração da análise crítica do discurso ideológico o enfrentamento de determinado uso de linguagem que se articula mediante a continuidade temporal e de escrita. Neste caso, evidencia-se a função crítica do fragmento como ruptura de elos causais a servirem à justificação do arranjo das 
forças dominantes em um dado momento histórico. É a esse respeito exemplar, por seu compromisso crítico, as Teses sobre filosofia da história. Busca problematizar os pressupostos que subjazem ao modo como amiúde se escreve a história. O objetivo é o de vincar os espaços de sua escrita na perspectiva dos vencidos, com o fito de desdobrar as muitas possibilidades vivenciadas no passado, mas das quais se guardou silêncio em nome do poder vigente.

$\mathrm{Na}$ organização das suas teses, o autor cuida em tornar coerentes entre si o conteúdo da sua denúncia e a disposição da escrita. Não Ihe basta desmontar os elementos ideológicos que sustentam a ideologia do progresso, importa também forjar no texto a encenação desse gesto crítico. $O$ trabalho consta de dezoito teses e dois apêndices. Entre si, não guardam articulação explícita, como se correspondessem em sua ruptura ao tema da descontinuidade temporal potencialmente revolucionária a que volta o filósofo em vários momentos do texto. Em algumas teses, revelando seu fascínio pelas técnicas vanguardistas, em especial com seus exercícios de montagem, as frases mesmas guardam certa independência, devido ao uso frugal de conjunções e outras partículas de coesão. O resultado impõe-se à não apenas pela integridade do seu esforço crítico, mas também por sua consumação artística.

É um dos seus intentos principais o de livrar a narrativa histórica de sistematizações homogeneizantes: "A história é resultado de uma construção, cujo lugar não é formado pelo tempo homogêneo e vazio, mas por aquele saturado pelo tempo-de-agora (Jetztzeit)" ${ }^{1}$. O "tempo-de-agora" a que se refere liga-se a três propósitos. Primeiramente, desmonta-se a noção de tempo em se estriba a ideia de progresso, marcado por traços lineares e homogêneos ${ }^{2}$. Deparamos, em vez disso, com um tempo-problema, complexo e indefinível em última instância, labirinto de mundos e ruínas. Em segundo lugar, concede relevo ao presente não mais submetido à teleologia do progresso, de modo que se possa desmontá-lo e lê-lo como fragmento, e não a parte de um todo que the conferisse sentido. Se nos furtamos a semelhante perspectivação, escapa-nos a marcha de movimentos autoritários que instam em cristalizar a história, ou organizá-la para fins dos

\footnotetext{
1 BENJAMIN, 2005, p. 119.

2 BENJAMIN, 2005, p. 116.
}

Gilmário Guerreiro da Costa - Pós-doutor pela Cátedra UNESCO Archai, da Universidade de Brasília. Pós doutorando no Centro de Estudos Clássicos e Humanísticos da Universidade de Coimbra. Professor da Universidade Católica de Brasília. Brasileiro, residente em Distrito Federal - Brasília, E-mail: gilmario.filosofia@gmail.com 
"inimigos", como diria Benjamin, assim estiolando-se os espaços de intervenção humana. Jeanne Marie Gagnebin evidencia a modorra que serve ao conformismo interiorizado, consequência de uma noção de história pretensamente orientada para o progresso; "O instante imobiliza esse desenvolvimento temporal infinito que se esvazia e se esgota e que chamamos - rapidamente demais — de história"3. A resposta de Benjamin à causalidade empobrecida é justo o tempo-de-agora, com as potencialidades abertas de se lutar por uma experiência histórica marcada pelo ineditismo, inscrita no horizonte da redenção.

\section{3.}

Nas teses benjaminianas sobressai, por seu lirismo e riqueza visual, a de número IX, na qual interpreta um quadro de Paul Klee, Angelus novus, imagem, a seu ver, do anjo da história. Figuras familiares na cultura judaico-cristã, anjos seriam entidades espirituais amiúde associadas ao serviço aos homens, mediadores entre estes e o divino: admoestação, incentivo, previsões, proteção, são algumas das ações nas quais se notabilizariam. No semblante do anjo do quadro Benjamin entrevê - ou projeta - um gesto atônito, de quem presenciou uma cena cujo terror o surpreende, e o impele a lançar voo. A descrição é acentuadamente visual. O filósofo vê um quadro: "Existe um quadro de Klee intitulado "Angelus Novus"”. Em seguida, focaliza uma parte, o anjo, e ainda mais especificamente, o modo intenso, algo comovido, do olhar: "Nele está representado um anjo, que parece estar a ponto de afastar-se de algo em que crava o seu olhar"5. A frase subsequente ainda mais insiste neste traço atônito, que se evidencia um pouco mais: "Seus olhos estão arregalados, sua boca está aberta e suas asas estão estiradas"6.

Certo perspectivismo da história poderia destarte nos revelar meandros de outro modo inacessíveis. Os próprios fragmentos das "Teses" são modos de olhar e de ser olhado. A montagem textual sobressai em detrimento da linearidade causal, ou antes, revela a perspectivação da própria causalidade. Benjamin move-se aqui com aparente destemor, assumindo diferenças de abordagem com respeito a alguns

\footnotetext{
3 GAGNEBIN, 1999, p. 97.

4 BENJAMIN, 2005, p. 87.

5 BENJAMIN, 2005, p. 87.

6 BENJAMIN, 2005, p. 87.
}

Gilmário Guerreiro da Costa - Pós-doutor pela Cátedra UNESCO Archai, da Universidade de Brasília. Pós doutorando no Centro de Estudos Clássicos e Humanísticos da Universidade de Coimbra. Professor da Universidade Católica de Brasília. Brasileiro, residente em Distrito Federal - Brasília, E-mail: gilmario.filosofia@gmail.com 
aspectos do materialismo histórico, mormente no caso da inter-relação causal entre infra e superestrutura. A metáfora do olhar como metáfora da história desponta como uma das grandes intuições desse texto, que segue até o seu arremate.

Ao dirigir o olhar para o passado, o anjo da história não se convence do elo entre os eventos havidos. Antes, sente-se impelido a quebrar as correntes, e fragmentar os fatos, assim procedendo a um inventário dos escombros que certa unidade textual intentava esconder. Chega mesmo a esboçar a intenção de despertar os mortos, de possivelmente confiar-Ihes algum segredo, alguma palavra. Mas algo mais forte o impede de fazê-lo: a tempestade do progresso, que define o futuro como campo da sua atividade. É um dos raros momentos em que o texto apresenta uma conjunção - por sinal, adversativa: "Mas do paraíso sopra uma tempestade que se emaranhou em suas asas e é tão forte que o anjo não pode mais fechá-las" ${ }^{7}$. O lamento perante o passado não pode demorar-se por força da urgência do progresso, em sua suposta marcha inapelável rumo ao futuro.

A frase que encerra a tese IX dimensiona, em sua construção, o movimento trágico entrevisto pelo anjo da história: iniciando com as luzes do progresso, o desfecho é a tempestade da barbárie: "O que nós chamamos de progresso é essa tempestade" "o progresso é essa tempestade." Esta inversão cumpre função importante no jogo do texto, ao despir de toda finalidade o progresso, quando for a barbárie o seu suporte. ${ }^{9} \mathrm{O}$ compromisso com a ideia de progresso implica o pressuposto de que estágios sucessivos no tempo realçam o aperfeiçoamento da história. O que ficou serve ao incremento do futuro, justificando sua existência. Nesse caso, pode-se lamentar o sofrimento passado, mas ele é reputado como necessário. No caso de pretendermos confrontar tais artimanhas ideológicas, não basta nos concentrarmos na exposição do tema. É necessária igualmente nos ocuparmos com o dilaceramento do texto passado, assim forçando as ruínas a prestarem testemunho

\footnotetext{
7 BENJAMIN, 2005, p. 87.

8 BENJAMIN, 2005, p. 87.

9 Essa meditação acerca do sofrimento sufocado na história comparece de modo pungente numa carta de 1935. Nela Benjamin alude aos horrores de que faz uso a civilização para soerguer-se; depois de lograr êxito, ela apaga os vestígios da destruição que perpetrou. Conferir: ARENDT, Hannah. Walter Benjamin: 1892-1940. in Homens em tempos sombrios. Trad. Denise Bottmann. São Paulo: Companhia das Letras, 1987. p. 165.
}

Gilmário Guerreiro da Costa - Pós-doutor pela Cátedra UNESCO Archai, da Universidade de Brasília. Pós doutorando no Centro de Estudos Clássicos e Humanísticos da Universidade de Coimbra. Professor da Universidade Católica de Brasília. Brasileiro, residente em Distrito Federal - Brasília, E-mail: gilmario.filosofia@gmail.com 
a partir das margens da história. O fragmento configura deste modo a dramatização da ruína, da catástrofe e do sofrimento, um tipo de pensar constituinte que encontra na linguagem poética foros de apresentação problemática do mundo, desrealizandoo criticamente, desconstruindo aquilo que se tomou como natureza. Nisso reside a dessacralização do mistério do olhar do anjo da história.

As ruínas da história são rememoradas nas ruínas do texto mesmo. Insinuamse os traços de um diálogo perdido, por força de violência ancestral, e que vigem nas frases algo independentes, como se a solidão moderna fosse levada para o seu interior. Subvertem-se a frase e a unidade do texto, assim resistindo aos significados estáveis que vigiam a escrita. Nota-se ainda a desconfiança com respeito a uma noção de tempo linear pressuposta numa configuração articulada e unitária de texto. Tal procedimento resulta em certo escândalo hermenêutico, haja vista desconfiar do contexto como instância de verdade - ele também é uma construção, não um dado. O contexto histórico é não raro um texto que insiste em recobrar independência. É necessário não nos impormos a obrigação servil de tomá-lo como instância a que acederíamos sem quaisquer mediações, de outro modo a escrita chegaria mesmo a legitimar a opressão, quando a unidade textual articula-se com a linearidade temporal, e ambas irmanam-se do discurso teleológico que sela a naturalização do movimento histórico. São modos que findam por justificar sub-repticiamente o conformismo da tradição. A montagem das teses benjaminianas condensa assim a força da denúncia, insistindo na importância ética, política e epistemológica de uma história dos vencidos, que possa fazer-nos atentar para o sofrimento surgido no palco da história. Outro escritor atento às margens e ruínas dos discursos triunfalistas, Guimarães Rosa, contribuirá com sua linguagem peculiar à presente discussão.

4.

Em meio aos seus múltiplos planos textuais, o romance Grande sertão: veredas desenvolve uma leitura crítica da história brasileira mediante recursos linguísticos que jogam recorrentemente com a ambiguidade. Pode-se sublinhar ao menos dois elementos desse exercício. O primeiro liga-se ao seu projeto narrativo, que se compromete com uma noção de ficção como busca da verdade por outras

Gilmário Guerreiro da Costa - Pós-doutor pela Cátedra UNESCO Archai, da Universidade de Brasília. Pós doutorando no Centro de Estudos Clássicos e Humanísticos da Universidade de Coimbra. Professor da Universidade Católica de Brasília. Brasileiro, residente em Distrito Federal - Brasília, E-mail: gilmario.filosofia@gmail.com 
vias - não são, nesse sentido, antitéticas, mas suplementares. Mas este movimento ficcional articula-se com o propósito de desvelar uma ficcionalidade viciada que se recusa a evidenciar os planos de violência e exclusão que se perpetuam na história brasileira. O segundo traço de ambiguidade toca a sua escrita, marcada pela fragmentação. Nos aforismos que se disseminam na narrativa lê-se, por um lado, o silêncio e perplexidade perante a carência material e o abandono da justiça em determinadas áreas do sertão brasileiro. Ao mesmo tempo, tais fragmentos, em gesto próximo à noção benjaminiana de história, é o que permite entrever algum aceno de esperança.

A ficção permite-nos configurar a imaginação de cenários alternativos ao plano presente do que se costuma chamar de realidade. Enseja cortes espaciais e temporais variados, tanto ao impor o distanciamento com respeito aos objetos que nos cercam, quanto ao desdobrar camadas temporais inauditas. Em ambos os casos, cria fissuras do discurso monolítico da verdade, ofertando a possibilidade de se divisar modos diferentes de ser. No limite, repõe em cenário crítico a ficcionalidade mesma do que chamamos de realidade. Por esse motivo, a ficção não se define por sua oposição à verdade, pois ambas compartilham um adversário comum: a mentira em todas as suas faces e fisionomias, entre as quais despontam a farsa e a manipulação.

Semelhante movimento é discernível no romance de Rosa. Mergulha nas distâncias do sertão e da história, mediante o recurso à imaginação e aos cortes espaço-temporais. Por seu intermédio, podemos ler sob tonalidade mais profunda o destino de parte da história brasileira. Apresenta-se um exercício ficcional em busca de verdades esquecidas seja pela indiferença dos homens, seja pela violência política. Simultaneamente, revela a montagem de certos discursos acerca do país, que justo por seus recursos de montagem, suscitam a desconfiança de embalar seus destinatários em uma ficção viciada que não se apresenta como tal. Revela-se, nesse sentido, o melhor aliado das ideologias do poder decantadas de toda aparência ficcional. Não bastaria, por essa razão, para desmontar seu jogo de dissimulação o enfrentamento com a razão crítica. Também importa o exercício irônico de restituí-la ao seu âmbito de fabulação.

Gilmário Guerreiro da Costa - Pós-doutor pela Cátedra UNESCO Archai, da Universidade de Brasília. Pós doutorando no Centro de Estudos Clássicos e Humanísticos da Universidade de Coimbra. Professor da Universidade Católica de Brasília. Brasileiro, residente em Distrito Federal - Brasília, E-mail: gilmario.filosofia@gmail.com 
Um aspecto peculiar à tessitura da ficção compreendeu-o muito bem 0 filósofo Paul Ricoeur ${ }^{10}$. Refere-se à alteração profunda da referência, quando o texto escrito não se circunscreve às intenções do seu autor, mas alcança autonomia. Além disso, a obra transcende seu contexto psicossociológico, abrindo-se a diversas leituras. Seu movimento vai da descontextualização à recontextualização efetuada pelo ato de ler. O distanciamento revela-se assim constitutivo da obra, é tanto o que se deve vencer, quanto o que condiciona a interpretação. Decorre desses mecanismos a alteração do funcionamento da referência: "o funcionamento da referência fica alterado quando não nos é mais possível mostrar a coisa de que falamos como pertencendo à situação comum aos interlocutores do diálogo" ${ }^{11}$. Mais especificamente, a literatura repõe em outro nível a questão da referência destruição do mundo para alcançá-lo em sua essência mais íntima. Sua potencialidade crítica reside nisso - abre fissuras mediante as quais se pode ainda pensar. Nesse espaço estético, evidencia-se uma demanda não apenas gnosiológica, mas também ética e política.

A análise do estatuto das relações entre ficção e realidade aprimora-se com o ensaio "O jogo do texto", de Wolfgang Iser ${ }^{12}$. O entrelaçamento que divisa entre autor, texto e leitor permite que cheguem a algo antes inexistente, assim problematizando a noção tradicional de representação. Disso decorre a perda de legitimidade da referência a uma realidade pré-estabelecida ${ }^{13}$. A tese avança ao defender a existência de um vínculo íntimo entre jogo e representação por força das mudanças modernas operadas na noção de mímesis ${ }^{14}$. Por conseguinte, a obra de ficção agora se lê não como duplo do mundo, mas encenação, jogo. Por inexistir uma instância prévia de sentido a que remeter-se com segurança, o seu significado configura-se mediante o uso de um suplemento, que enseja a conformação de uma cena afim à multiplicidade interpretativa. Desestabilizam-se, dessa maneira, o espaço e tempo do autor, do texto e do leitor ${ }^{15}$, os quais se relacionam, nesse novo quadro, a partir de três níveis: estrutural, funcional e interpretativo.

\footnotetext{
${ }^{10}$ RICOEUR, 2008.

${ }^{11}$ RICOEUR, 2008, p. 63.

12 ISER, 2002.

${ }^{13}$ ISER, 2002, p. 105.

${ }^{14}$ ISER, 2002, p. 107.

${ }^{15}$ ISER, 2002.
}

Gilmário Guerreiro da Costa - Pós-doutor pela Cátedra UNESCO Archai, da Universidade de Brasília. Pós doutorando no Centro de Estudos Clássicos e Humanísticos da Universidade de Coimbra. Professor da Universidade Católica de Brasília. Brasileiro, residente em Distrito Federal - Brasília, E-mail: gilmario.filosofia@gmail.com 
O nível estrutural remete aos espaços da obra. Em um dos momentos mais profícuos do ensaio, Iser apresenta o conceito de "significante fraturado", por cujo intermédio se modelam a fratura e frustração referenciais. Seu uso figurativo tem indicação ficcional assente numa estrutura de como se. Esse amanho estrutural e figurativo evidencia a cumplicidade por vezes tensa, mas recorrente, entre autor e leitor na cena do texto ${ }^{16}$. Funciona assim como figura de um paradoxo: sua presença amolda os fios de algo ausente, de uma denotação que não pode rematar-se perfeitamente sob pena de oferecer o desengano de um sucesso aparente. Um pouco adiante, em uma formulação feliz, o autor arremata: "o significante fraturado simultaneamente denotativo e figurativo - invoca alguma coisa que não é pré-dada pelo texto mas engendrado por ele, que habilita o leitor a dotá-lo de uma forma tangível". 17

O nível funcional descerra mudanças nos signos da representação, transformando-a de modo a fundar novas possibilidades de ler e existir ${ }^{18}$. No jogo complexo que entretém com o leitor, o texto enseja uma performance que pouco ou nada tem de comum com a mera decifração. Antes, a leitura reinventa-se no entretecimento lúdico dos signos, subvertendo um dualismo estanque entre sujeito e objeto, e move o plano múltiplo no qual se interpenetram texto e leitor, na qual nunca se é tão somente si mesmo. Nesse itinerário, o ato de interpretar tece um suplemento sempre residual, em um diálogo que nunca é arbitrário, mas tampouco o desfecho dos elos de significação de uma obra.

O nível interpretativo revela uma dupla necessidade a que o jogo textual satisfaz: epistemológica, uma vez que esse jogo nega "realidades" extratextuais, legitimando a busca por repensar-se o mundo a que o texto concedeu presença e ausência; e antropológica, pois encenamos a posse do que nos é amiúde recusado - a precariedade ontológica do mundo no qual estamos imersos, numa inestimável contribuição à defesa da importância da literatura ${ }^{19}$.

Toda essa orientação, no entanto, ainda sofre de certo otimismo teleológico, a pressupor sujeitos livres e dispostos a se deixarem provocar pelo jogo do texto. Ao

\footnotetext{
${ }^{16}$ ISER, 2002, p. 110.

${ }^{17}$ ISER, 2002, p. 110.

18 ISER, 2002, p. 115.

${ }^{19}$ ISER, 2002, p. 118.
}

Gilmário Guerreiro da Costa - Pós-doutor pela Cátedra UNESCO Archai, da Universidade de Brasília. Pós doutorando no Centro de Estudos Clássicos e Humanísticos da Universidade de Coimbra. Professor da Universidade Católica de Brasília. Brasileiro, residente em Distrito Federal - Brasília, E-mail: gilmario.filosofia@gmail.com 
conceito de "significante fraturado" importa acrescentar o de "fracasso teleológico", um operador que permitiria a um crítico radicalizar sua vocação à suspeita e à desconfiança. É um processo ambíguo, por um lado, a acenar utopicamente para a possibilidade da emancipação, por outro, a alegoria dos obstáculos à consecução precisamente desse pressentimento utópico. No que se refere especificamente à ficção de Guimarães Rosa, pode-se presumir um nível de provocação a que os seus leitores resistiriam mesmo com indiferença. Malgrado as ressalvas às expectativas idealistas observáveis na teoria de Iser, parece-nos esclarecer, juntamente com a reflexão ricoeuriana supra-examinada, alguns aspectos da peculiaridade dos textos ficcionais, peça de relevo no estudo do romance de Guimarães Rosa.

\section{5.}

A caracterização da natureza brasileira foi objeto de numerosos relatos idealizados, os quais a apresentavam a partir do topos recorrente do locus amoenus. Rosa procede consistentemente à sua desmonstagem. O romance de formação do Brasil, para nos servirmos da tese de Willi Bolle ${ }^{20}$, revisita e subverte as narrativas da idade de ouro. Uma fonte sobremodo fecunda para o seu exame é o livro Visão do paraíso, de Sérgio Buarque de Holanda. Nele o autor serve-se da hipótese de haver sido certa visão idealizada de terras distantes um elemento crucial de motivação das viagens colonizadoras europeias nos séculos XV, XVI e XVII. As fontes de motivos edênicos recuam à Idade Média, com a crença de que o Paraíso Terreno situa-se concretamente em alguma parte esquecida do mundo, que viria a ser objeto de busca ostensiva de aventureiros e peregrinos. O tema das visões da Paraíso inicia-se no século IV e se aperfeiçoou através dos séculos, conhecendo intensa persistência na memória de muitos ${ }^{21}$. Tais impulsos repercutem consideravelmente nos motivos organizadores da colonização da América, seja a anglo-saxã, seja a latina, posto que seus desejos e projetos se diferenciassem consideravelmente um do outro.

Esse itinerário de investigação exigiu do autor esclarecimentos metodológicos. Admite o suporte material de muitos elementos de que se ocupa,

\footnotetext{
${ }^{20}$ BOLLE, 2004. Falta o número da página.

${ }^{21}$ HOLANDA, 1996, p. X.
}

Gilmário Guerreiro da Costa - Pós-doutor pela Cátedra UNESCO Archai, da Universidade de Brasília. Pós doutorando no Centro de Estudos Clássicos e Humanísticos da Universidade de Coimbra. Professor da Universidade Católica de Brasília. Brasileiro, residente em Distrito Federal - Brasília, E-mail: gilmario.filosofia@gmail.com 
desde que não o comprometa com um uso unilateral das categorias marxistas de infra e superestrutura. Como prova de resistência a tal espírito dogmático, sublinha o fato de que as ideias, ao migrarem no tempo e no espaço, podem fecundar novas realidades.

Examina então alguns motivos edênicos presentes no imaginário dos navegadores europeus à época das viagens de colonização da América. Sobressaem a fonte da juventude, a ilha de mulheres e as amazonas. Esta tópica das visões do Paraíso é observável nas viagens e textos de Cristóvão Colombo, cujas descrições foram especialmente afetadas por esse imaginário ${ }^{22}$. Alguns desses temas, mormente aqueles ligados à fonte da juventude, poderiam ter sido sugeridos aos conquistadores mediante a leitura de novelas de cavalaria ${ }^{23}$. Esses elementos, articulados com a esperança de se encontrar tesouros no interior do Brasil, impulsionaram diversas entradas. Muitas expedições eram movidas pelo sonho de descobrir-se no Brasil um "outro Peru" ${ }^{24}$. A geografia mítica do país, portanto, enfeixava-se amiúde em motivos edênicos.

Motivos referentes à Idade de Ouro, retirados a Ovídio, são recorrentes entre os cronistas da conquista. Com ela se pretendia referir-se a uma era amiúde associada à excelência do estado natural. Resultava na afirmação da bondade natural do homem, ideia que deixou grande lastro:

\footnotetext{
é um traço da aurea aetas dos antigos, ou com as opiniões eclesiásticas e, em verdade, cristãs, sobre o statu innocentiae, compendiadas na Suma Teológica de S. Tomás de Aquino, que um e outras, por intermédio talvez de Montaigne e, em menor grau, de Las Casas, hão de frutificar, com o tempo, no postulado, rico em consequências, da bondade natural do homem ${ }^{25}$.
}

O pessimismo inscrito na ideia de Queda não desautorizou a crença no Paraíso terrestre. Viu-se antes robustecida pela mudança de mentalidade franqueada pelo Humanismo, que esbate o pessimismo antropológico medieval. Esclarecem-se um pouco mais os meandros desse percurso histórico mediante a polêmica em torno à existência de ruptura ou continuidade entre Idade Média e Renascença. Sugerindo, em grande medida, a superação dialética destas teses,

\footnotetext{
${ }^{22}$ HOLANDA, 1996, p. 16.

${ }^{23}$ HOLANDA, 1996, p. 32.

${ }^{24}$ HOLANDA, 1996, p. 103

${ }^{25}$ HOLANDA, 1996, p. 187
}

Gilmário Guerreiro da Costa - Pós-doutor pela Cátedra UNESCO Archai, da Universidade de Brasília. Pós doutorando no Centro de Estudos Clássicos e Humanísticos da Universidade de Coimbra. Professor da Universidade Católica de Brasília. Brasileiro, residente em Distrito Federal - Brasília, E-mail: gilmario.filosofia@gmail.com 
Sérgio Buarque afirma o caráter crepuscular da mudança, na qual tanto entram elementos otimistas, extremados na afirmação das potencialidades humanas e da natureza, quanto a desconfiança com respeito à possível confirmação da miséria da criatura $^{26}$. Ora se sublinha a salvação circunscrita ao plano extramundano, ora se delineia a esperança neste mundo, em algum sítio incontaminado.

O "novo mundo" revela-se especialmente propenso a esse afã edênico. O caráter supostamente matinal da natureza americana o incentivava, como se a aproximar-se da uma Idade de Ouro. Tocamos aqui um tema recorrente entre os escritores clássicos, o do locus amoenus:

\begin{abstract}
E ainda quando cedem, porventura, ao prestígio dos loci amoeni clássicos, tão comumente seguidos nas descrições da época, são levados, talvez insensivelmente, a podá-los das frondosidades fantásticas, geralmente inseparáveis do antigo esquema. ${ }^{27}$
\end{abstract}

Em página admirável de literatura comparada, 0 autor retira ricas consequências dessa discussão a partir de um confronto entre Horácio e Sêneca. Ao primeiro coube a defesa de certos limites na representação de cenas violentas, tais como as de Medeia ao assassinar os próprios filhos. Cumpria que semelhante desenlace ocorresse nos bastidores, chegando ao público tão somente o relato do temível evento. Sêneca, ao invés, oferece ao público precisamente a representação do descalabro e da violência: ver-se-á no palco Medeia, em fúria desabalada, precipitar-se contra os filhos, tirando-lhes a vida. Tal exercício serve ao arremate de uma argumentação que pode ser sumariada com esta pergunta: a natureza sensível nos franquearia algum conhecimento do espiritual - verdadeiro e invisível?

Guimarães Rosa reconfigura esses temas em seu romance por via de uma operação alegórica que faz sobressair não mais a expectativa edênica, mas a ambiguidade. Não raro será por via de uma reflexão acerca da natureza que seu romance enredará um tema afim ao Barroco, do qual essa narrativa é em grande medida herdeira: o desconcerto do mundo. A ideia de locus amoenus fragmenta-se por entre as imagens do sertão, algumas delas comprometidas por uma reflexão acerca do mal que ameaça a existência humana, em geral, e os limites da

\footnotetext{
${ }^{26}$ HOLANDA, 1996, p. 189

27 HOLANDA, 1996, p. 244.
}

Gilmário Guerreiro da Costa - Pós-doutor pela Cátedra UNESCO Archai, da Universidade de Brasília. Pós doutorando no Centro de Estudos Clássicos e Humanísticos da Universidade de Coimbra. Professor da Universidade Católica de Brasília. Brasileiro, residente em Distrito Federal - Brasília, E-mail: gilmario.filosofia@gmail.com 
sobrevivência de grupos sociais diversos nos campos gerais do Brasil. Fornece sinais inequívocos de uma leitura crítica da história do país.

6.

A desconfiança com as imagens idealizadas da natureza brasileira compõe parte considerável da teia narrativa do Grande sertão: veredas. Os planos do sertão, espaço por excelência da obra, convergem para esse propósito. Conforma um espaço sertanejo marcado pela multiplicidade semântica e por traços ambíguos, tanto eivado de beleza e encanto, quanto a alegoria do desconcerto do mundo e do mal, seja ontológico, seja social. O sertão rosiano é assim urdido de modo complexo, por um lado recortando a geografia do interior de Minas Gerais, por outro construindo planos alegóricos de corte mais universal.

Em uma das primeiras cartas enviadas a Curt Meyer-Classon, seu tradutor alemão, o escritor mineiro faz uma ponderação que deixa surpreender um gosto cosmopolita que a circunscrição regional do espaço das suas narrativas nunca negou: "A tradução e publicação em alemão me entusiasma, por sua alta significação cultural, e porque julgo esse idioma o mais apto a captar e refletir todas as nuances da língua e do pensamento em que tentei vazar os meus livros." 28 Tristão de Ataíde sustenta haver em nossos melhores escritores a busca por articular o nacional com o universal. Em Guimarães Rosa não é diferente. O mero rótulo de "escritor regionalista", sobre ser insuficiente, conduz mesmo à incompreensão de sua obra:

a paisagem e a palavra desempenham um papel muito importante em sua expressão estética e tanto uma como outra em estreita ligação com a realidade sertaneja. Mas nada é mais estranho à sua literatura do que o regionalismo. ${ }^{29}$

O autor credita a esta mescla tão bem sucedida o interesse internacional pela obra do escritor mineiro, atestado nas muitas traduções que recebeu, em grande medida afinadas com o universalismo que algumas faces do sertão rosiano permitem divisar.

\footnotetext{
${ }^{28}$ Carta de 18/02/1959. ROSA, 2003, p. 70.

${ }^{29}$ ATAÍ́DE, 1991, p. 143.
}

Gilmário Guerreiro da Costa - Pós-doutor pela Cátedra UNESCO Archai, da Universidade de Brasília. Pós doutorando no Centro de Estudos Clássicos e Humanísticos da Universidade de Coimbra. Professor da Universidade Católica de Brasília. Brasileiro, residente em Distrito Federal - Brasília, E-mail: gilmario.filosofia@gmail.com 
A esse respeito, Nelly Novaes Coelho sustenta que a distância entre Guimarães Rosa e os escritores regionalistas reside em que estes ocupam-se com o projeto de uma "palavra-depoimento", enquanto aquele privilegia a "palavrainvenção". São concepções sobremodo divergentes. Os regionalistas percebiam a urgência da denúncia de um meio injusto. Rosa, por seu turno, julgava este afã inoperante sem a sublevação da linguagem movida por uma sorte de intervenção poética: "E nessa ordem de ideias, podemos afirmar que a renovação rosiana na área da ficção regionalista teve início pela substituição da palavra-depoimento (própria do homo sapiens) pela palavra-invenção (do homo ludens). ${ }^{30} \mathrm{~A}$ palavra "substituição" talvez seja inapropriada, pois se compromete com uma dicotomia pouco fecunda e inadequada ao ambiente ambíguo do romance rosiano. Seria plausível a conjetura de um posicionamento textual, no qual mesmo a palavradepoimento trairia a sua invenção, depondo contra o pressuposto de uma referencialidade feliz, pois jazem sob suspeita precisamente os termos "linguagem" e "realidade".

Manifesta-se deste modo uma narrativa entretecida por via diversa à do regionalismo literário strictu sensu. A especificidade do tratamento artístico que oferece ao espaço sertanejo é analisada por Antonio Candido, por meio de um confronto com Os sertões, de Euclides da Cunha. De modo lapidar, assim os diferencia: "a atitude euclideana é constatar para explicar, e a de Guimarães Rosa inventar para sugerir." ${ }^{31}$ De fato, sugestão é traço inerente ao sertão rosiano, intimamente associada ao trato linguístico e à articulação fragmentária com as quais esse romance desafia com frequência os seus leitores: "um universo que ultrapassa a pura referencialidade e se institui como espaço eminente da criação."32

Seja a especificidade regional, sejam os seus traços universalistas são tecidos por uma linguagem em que tem relevo a criação recorrente, com a qual se dá a ler ao leitor um mundo também sob a transgressão do novo que brota incontinenti. Configuram modos de subverter processos de cristalização da linguagem e do mundo, sob o primado do significado e da Realidade, desse modo encenando possibilidades de enfraquecimento de estruturas de poder que

\footnotetext{
${ }^{30}$ COELHO, 1991, p. 258.

${ }^{31}$ CANDIDO, 1991, p. 295-6.

${ }^{32}$ COUTINHO, 1994, p. 19.
}

Gilmário Guerreiro da Costa - Pós-doutor pela Cátedra UNESCO Archai, da Universidade de Brasília. Pós doutorando no Centro de Estudos Clássicos e Humanísticos da Universidade de Coimbra. Professor da Universidade Católica de Brasília. Brasileiro, residente em Distrito Federal - Brasília, E-mail: gilmario.filosofia@gmail.com 
beneficiam frequentemente apenas a uns poucos grupos. Em termos benjaminianos, revela o momento de decisão que se subtrai a uma pretensa cadeia de eventos históricos por meio da ruptura de um tempo-de-agora. Embora sem atender ao mesmo apelo revolucionário que movimenta a reflexão benjaminiana, a narrativa rosiana também confia à ruptura de certa urdidura textual as possibilidades mais generosas de revelação da verdade da ficção justo na fratura mesma das frases. Não deixa de surpreender que este projeto se tenha efetivado em um autor que, diferentemente dos escritores regionalistas afinados com perspectivas políticas revolucionárias, desmentia qualquer filiação ideológica explícita, sobretudo de esquerda. Estaríamos diante de um caso paradoxal que traiu, nos traços conservadores de sua figura, uma visão crítica modelar e algo profética dos (des) caminhos da formação da sociedade brasileira.

O sertão apresenta-se na obra, além disso, mediante tentativas sucessivas e renitentes de definição, as quais nunca ofertam o perfil consumado do seu objeto. Antes, tornam-se em inusitados aforismos: "O sertão é do tamanho do mundo" ${ }^{33}$, "Sertão é o sozinho"34, "O sertão é sem lugar"35, "O sertão é uma espera enorme"36. Esta é uma pequena amostra das perspectivas oferecidas a esse espaço tecido em linguagem. Nessas frases o verbo "ser" parece desmentir atributos substancialistas. Esboçam apenas traços do sertão, pois ele não tem lugar. Aproximam-se por essa via de uma premissa trágica por excelência: a da irredutibilidade predicativa. Em vez da representação confiante da realidade, expõem-se ao silêncio e ao tempo.

A circunscrição regional do sertão rosiano, que ele em muitas passagens realça, é também um entrelaçamento geográfico-político: "sertão é onde manda quem é forte, com as astúcias. Deus mesmo, quando vier, que venha armado!" ${ }^{37}$. A história brasileira é suficientemente replena de injustiças e violência para que semelhante sertão bem Ihe seja a alegoria. Walnice Nogueira Galvão, em estudo acerca das relações entre o texto rosiano e o texto da história brasileira, nota que o "exercício privado e organizado da violência"38 foi recorrente nesses espaços. Mas

\footnotetext{
${ }^{33}$ ROSA, 1994, p. 52.

${ }^{34}$ ROSA, ANO, p. 199. Tinha apenas o número da página.

${ }^{35}$ ROSA, ANO, p. 227. Tinha apenas o número da página.

${ }^{36}$ ROSA, ANO, p. 365. Tinha apenas o número da página.

${ }^{37}$ ROSA, ANO, p. 18. Tinha apenas o número da página.

${ }^{38}$ GALVÃO, 1972, p. 21.
}

Gilmário Guerreiro da Costa - Pós-doutor pela Cátedra UNESCO Archai, da Universidade de Brasília. Pós doutorando no Centro de Estudos Clássicos e Humanísticos da Universidade de Coimbra. Professor da Universidade Católica de Brasília. Brasileiro, residente em Distrito Federal - Brasília, E-mail: gilmario.filosofia@gmail.com 
não apenas isso. Nesses espaços habita toda uma multidão de miseráveis, vítimas de desmandos ancestrais que a história brasileira ainda não logrou êxito em apresentar a esperada solução. Observe-se a cena temível que segue, em que a miséria e a desolação sobem ao proscênio como poucas vezes na literatura brasileira:

\begin{abstract}
Com outros nossos padecimentos, os homens tramavam zuretados de fome - caça não achávamos - até que tombaram à bala um macaco vultoso, destrincharam, quartearam e estavam comendo. Provei. Diadorim não chegou a provar. Por quanto - juro ao senhor - enquanto estavam ainda mais assando, e manducando, se soube, o corpudo não era bugio não, não achavam o rabo. Era homem humano, morador, um chamado José dos Alves! Mãe dele veio de aviso, chorando e explicando: era criaturo de Deus, que nu por falta de roupa... Isto é, tanto não, pois ela mesma ainda estava vestida com uns trapos; mas o filho também escapulia assim pelos matos, por da cabeça prejudicado. Foi assombro. A mulher, fincada de joelhos, invocava. ${ }^{39}$
\end{abstract}

Esta passagem é construída com notável economia de adjetivos e a necessária rudeza. A cultura parece desfazer-se progressivamente dos seus traços distintivos. Homens famintos devoram outro homem que confundiram com um símio. Não poderia ser mais desconcertante: não foram capazes de reconhecer a outro homem? Estranha sorte de dialética de senhores e miseráveis, sem passagem ao reconhecimento. A mãe chega correndo, aos gritos, a implorar o respeito ao corpo morto do filho: "A mulher, fincada de joelhos, invocava". Informa-se concisamente o efeito da revelação: "Foi assombro". A imagem dessa mulher andrajosa, misto de pietá e suplicante, a lamentar o terrível martírio do filho, convida a uma leitura da nação no horizonte dessa escrita afeita às margens da linguagem e da história.

Adiante Riobaldo observa: "O senhor sabe: tanta pobreza geral, gente no duro ou no desânimo. Pobre tem de ter um triste amor à honestidade. São árvores que pegam poeira" ${ }^{40}$. As duas últimas frases são notáveis pela recusa a algum consolo que funcionasse como substituto desse quadro de escassez. O narrador rejeita qualquer sorte de adereço vicário da pobreza que testemunha. A honestidade, valor cultivado por esses homens pobres, desfaz-se de traços épicos, pois se vincula a um misto de amor (pela virtude) e tristeza (pela seu abandono). $\mathrm{Na}$ última frase sobressai um construto metafórico inusitado. Os pobres são

\footnotetext{
${ }^{39}$ ROSA, 1994, p 40.

${ }^{40}$ AUTOR, ANO, p. 51. Tinha apenas o número da página.
}

Gilmário Guerreiro da Costa - Pós-doutor pela Cátedra UNESCO Archai, da Universidade de Brasília. Pós doutorando no Centro de Estudos Clássicos e Humanísticos da Universidade de Coimbra. Professor da Universidade Católica de Brasília. Brasileiro, residente em Distrito Federal - Brasília, E-mail: gilmario.filosofia@gmail.com 
comparados a árvores expostas à poeira da estrada. Por um lado, sublinham-se as suas raízes profundas, emblema dos valores a que se liga (honestidade), por outra lado, em vez da exuberância da cor ou do formato, acrescenta-se que "pegam poeira". O seu movimento não logra expulsar a sujidade de mundo que se vai acumulando. Mais uma peça decisiva na desmontagem da natureza como locus amoenus - por vezes, sua figura mais própria nos labirintos do sertão não é o paraíso terreno, mas os signos de uma maquinaria infernal.

7.

Willi Bolle refere-se ao romance de Rosa como "uma releitura da história do Brasil” $^{41}$. A assertiva implica uma visada crítica no processo de formação da sociedade brasileira, marcada por violência exercida em variados âmbitos e por uma cisão entre as classes, visível na ausência de diálogo que as nossos elites propugnaram por manter, em seu gesto altivo de distanciamento. A esse respeito, os aforismos rosianos oferecerão algumas janelas pelas quais se pode testemunhar aspetos dessa violência histórica: "no texto de Grande Sertão: Veredas, os fragmentos esparsos de uma história criptografada, que o leitor é incentivado a reorganizar"42. Trata-se, por essa razão, de uma "história da formação a partir do Mal" ${ }^{43}$.

Apresenta-se assim um projeto audacioso de prover meios para se refletir sobre o significado de um romance de formação no Brasil que articule, assim como foi encontradiço em Goethe, um exercício de diálogo entre as classes: "É o romance de formação do país, na medida em que o autor, através da invenção de linguagem, refinou o medium para este país se pensar a si mesmo"44. Todavia, convém pensar os limites desse diálogo via Marx e Freud, ou seja, presumir a possibilidade de as distorções de significado e os planos de fingimento oferecerem apenas uma caricatura de um efetivo encontro entre os homens.

A referida falta de diálogo entre as classes é especialmente visível no episódio trágico de Canudos. Mas também ostensivo em nossos dias, revelando-se

\footnotetext{
${ }^{41}$ BOLLE, 2004, p. 7.

${ }^{42}$ BOLLE, 2004, p. 9.

${ }^{43}$ BOLLE, 2004, p. 9.

${ }^{44}$ BOLLE, 2004, p. 10.
}

Gilmário Guerreiro da Costa - Pós-doutor pela Cátedra UNESCO Archai, da Universidade de Brasília. Pós doutorando no Centro de Estudos Clássicos e Humanísticos da Universidade de Coimbra. Professor da Universidade Católica de Brasília. Brasileiro, residente em Distrito Federal - Brasília, E-mail: gilmario.filosofia@gmail.com 
uma das causas precípuas da não emancipação do país ${ }^{45}$. É nesse sentido que o autor sugere que se interprete o pacto e o diabólico no Grande sertão como alegorias da separação que grassou a história do país ${ }^{46}$. Adiante o autor refere-se a "um Mal social". Avança uma investigação que Ihe dará azo a fecunda aproximação entre Rosa e Benjamin. Em ambos os casos, trata-se de se resistir aos gestos de harmonização do poder, por meio do seu desnudamento. Seu exercício de escrita fragmentária articula-se com uma temporalidade descontínua, recursos passíveis de conceder a forma crítica coerente ao tema de que se ocupam - seja uma reflexão acerca da escrita da história, em Benjamin, seja das assimetrias sociais, em Rosa ${ }^{47}$.

É assim a partir de leitura de profundo extrato político que Bolle interpreta o pacto no romance. Descerra a alegoria da lei fundadora, do contrato social:

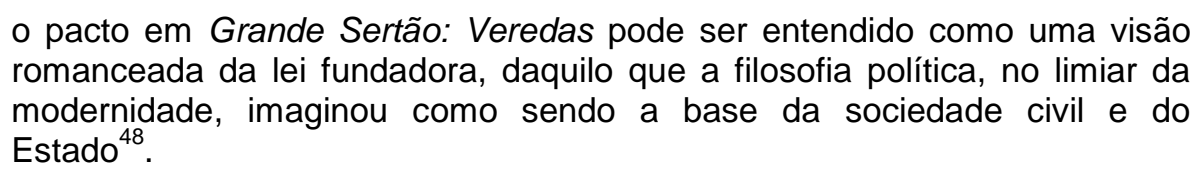

Em vez de legitimação do status quo, encontramos antes um sentimento de culpa no protagonista do romance, Riobaldo. Ele abisma-se na memória com o fito de revisitar as entranhas do bem e do mal, seja em cifra metafísica, seja em enfrentamento da concretude da matéria social - duas instâncias complementares na obra.

O âmbito da culpa sublinha a peculiaridade do exercício da memória em Rosa. É um ponto de afastamento dele com respeito a Sérgio Buarque - não se pretende aniquilar as raízes ibéricas, possível causa de alguns dos males sociais mais persistentes em nossa história. Antes, Rosa reaproxima-se desses elementos num esforço de rememoração a par com o enfrentamento da culpa: "os erros e os crimes, em vez de serem liquidados, aniquilados, extirpados - e, com isso, recalcados -, são trazidos à luz do dia, com a expectativa de uma redenção" ${ }^{49}$. Pelas fissuras do percurso que se reencena, espera-se algum vislumbre de redenção. No entanto, nesse contraste apresenta-se quadro um tanto reducionista

\footnotetext{
${ }^{45}$ BOLLE, 2004, p. 17.

${ }^{46}$ BOLLE, 2004, p. 18.

${ }^{47}$ BOLLE, 2004, p. 123.

${ }^{48}$ BOLLE, 2004, p. 155-6.

${ }^{49}$ BOLLE, 2004, p. 319.
}

Gilmário Guerreiro da Costa - Pós-doutor pela Cátedra UNESCO Archai, da Universidade de Brasília. Pós doutorando no Centro de Estudos Clássicos e Humanísticos da Universidade de Coimbra. Professor da Universidade Católica de Brasília. Brasileiro, residente em Distrito Federal - Brasília, E-mail: gilmario.filosofia@gmail.com 
de Sérgio Buarque, ou no mínimo sua apresentação próxima a um autor insensível aos apelos da rememoração. As duas posições não são, entretanto, absolutamente excludentes - convém esmaecer-se o antagonismo apresentado.

Não estamos diante da memória de um Brasil soterrado. Do mal ontológico, universal, vemos-lhe a concretização no cenário rural, espelho de um outro Brasil, moderno e urbanizado, não isento das suas próprias perplexidades. É nesse contexto que os aforismos rosianos montam incômodos tribunais lançados não raro sobre a própria linguagem. Nessas encruzilhadas do caminho, instrui alguns dos gestos mais efetivos de resistência crítica a certa ficção do Brasil, sub-repticiamente oculta sob trajes ideológicos diversos. A exemplo de Walter Benjamin, parece pouco convencido com a tonalidade triunfalista de certa celebração do progresso que se faz às expensas da própria história. 


\section{REFERÊNCIAS}

ARENDT, Hannah. Walter Benjamin: 1892-1940. In.: Homens em tempos sombrios. Trad. Denise Bottmann. São Paulo: Companhia das Letras, 1987.

ATAÍDE, Tristão de. O transrealismo de G. R. In.: COUTINHO, Eduardo (org.). Guimarães Rosa. 2a ${ }^{\mathrm{a}}$. ed. Rio de Janeiro: Civilização Brasileira, 1991. (Coleção Fortuna Crítica).

BENJAMIN, Walter. Teses "Sobre o conceito de história". Tradução de Jeanne Marie Gagnebin e Marcos Müller. In.: LÖWY, Michael. Aviso de incêndio: uma leitura das teses "Sobre o conceito de história". Tradução de Wanda Nogueira C. Brant, [tradução das teses] Jeanne Marie Gagnebin e Marcos Müller. São Paulo: Boitempo, 2005.

BOLLE, Willi. grandesertão.br: o romance de formação do Brasil. São Paulo: Duas Cidades; Ed. 34, 2004.

CANDIDO, Antonio. O homem dos avessos. In.: COUTINHO, Eduardo (org.). Guimarães Rosa. 2a ${ }^{\mathrm{a}}$. ed. Rio de Janeiro: Civilização Brasileira, 1991. (Coleção Fortuna Crítica).

COELHO, Nelly Novaes. Guimarães Rosa e o Homo ludens. In.: COUTINHO, Eduardo (org.). Guimarães Rosa. 2 ${ }^{\mathrm{a}}$. ed. Rio de Janeiro: Civilização Brasileira, 1991. (Coleção Fortuna Crítica).

COUTINHO, Eduardo (org.). Guimarães Rosa. $2^{\mathrm{a}}$. ed. Rio de Janeiro: Civilização Brasileira, 1991. (Coleção Fortuna Crítica).

Guimarães Rosa: um alquimista da palavra. In.: ROSA, Guimarães. Fiç̧ão completa. Rio de Janeiro: Nova Aguilar, 1994. V. 1, p. 19.

GALVÃO, Walnice Nogueira. As formas do falso: um estudo sobre a ambigüidade no Grande-sertão: veredas. São Paulo: Perspectiva, 1972.

GAGNEBIN, Jeanne Marie. História e narração em Walter Benjamin. $2^{\mathrm{a}}$. ed. São Paulo: Perspectiva, 1999.

HOLANDA, Sérgio Buarque de. Visão do Paraíso: os motivos edênicos no descobrimento e colonização do Brasil. 6⿳亠丷. . ed. São Paulo: Brasiliense, 1996.

ISER, Wolfgang. O jogo do texto. In.: LIMA, Luiz Costa. Org. e trad. A literatura e o leitor: textos de estética da recepção. $2^{\mathrm{a}}$. edição revista e ampliada. Rio de Janeiro: Paz e Terra, 2002.

LÖWY, Michael. Aviso de incêndio: uma leitura das teses "Sobre o conceito de história". Tradução de Wanda Nogueira C. Brant, [tradução das teses] Jeanne Marie Gagnebin e Marcos Müller. São Paulo: Boitempo, 2005.

Gilmário Guerreiro da Costa - Pós-doutor pela Cátedra UNESCO Archai, da Universidade de Brasília. Pós doutorando no Centro de Estudos Clássicos e Humanísticos da Universidade de Coimbra. Professor da Universidade Católica de Brasília. Brasileiro, residente em Distrito Federal - Brasília, E-mail: gilmario.filosofia@gmail.com 
RICOEUR, Paul. Interpretação e ideologias. Org. e trad. Hilton Japiassu. Petrópolis, R.J.: Vozes, 2008.

ROSA, Guimarães. Correspondência com seu tradutor alemão Curt MeyerClasson (1958-67). Edição, organização e notas Maria Apparecida F. M. Bussolotti; tradução Erlon José Paschoal. Rio de Janeiro: Nova Fronteira / Academia Brasileira de Letras; Belo Horizonte, Ed. UFMG, 2003.

Aguilar, 1994. Vol. 2.

Grande sertão: veredas. In Ficção completa. Rio de Janeiro: Nova 